\title{
True Costs of Construction Accidents: Hidden Incentive for Construction Automation and Robotics
}

\author{
JOHN G. EVERETT
}

Assistant Professor, Dept. of Civil and Environmental Engineering, University of Michigan, 2352 G. G. Brown Lab, Ann Arbor, MI 48109-2125 USA.

\section{Abstract}

One of the frequently cited drivers for automation and robotics in construction is the potential improvement in safety. Much of the publicly funded research in this area is in exotic and very hazardous applications such as space construction, underwater construction, and clean-up of nuclear and other contaminated sites. These applications, however, make up only a small fraction of the total construction volume. The vast majority of construction projects are more mundane but collectively far more dangerous. This paper exposes the true impact of a contractor's loss experience on its WCI costs and bottom line. When contractors realize they are paying for their own losses and are effectively self-insuring, they may have increased incentive to improve their safety performance. Construction automation and robotics may suddenly seem more attractive and cost effective.

\section{INTRODUCTION}

One of the frequently cited drivers for automation and robotics in construction is the potential improvement in safety. Much of the publicly funded research in this area is in exotic and very hazardous applications such as space construction, underwater construction, and clean-up of nuclear and other contaminated sites. These applications, however, make up only a small fraction of the total construction volume. The vast majority of construction projects are more mundane but collectively far more dangerous. Each year for the past decade, roughly 2,000 people have been killed and 300,000 injured in the U.S. construction industry. The total cost to the nation, to employers, and to individuals is estimated to be about $\$ 780,000$ per fatality and $\$ 27,000$ per disabling injury (Accident 1993).

For contractors, the costs of insuring against occupational injuries, illnesses, and fatalities has increased dramatically in recent years. Over the last eight years, workers' compensation insurance (WCI) rates for three key trades: carpenters, bricklayers, and structural ironworkers, have increased an average of $10.5 \%$ per year to the current national average level of about $\$ 28$ per $\$ 100$ of payroll (Grogan 1993). For comparison, the national average in 1984 was $\$ 10.64$ per $\$ 100$ of payroll („Insurance” 1984). Over the last eight years, wage rates for the key trades increased only $3.2 \%$ per year (Grogan 1993). It is expected that WCI costs will continue to rise.

Most contractors regard WCI as an outrageously expensive, but necessary cost of doing business. Many contractors believe that WCI spreads the costs of their losses throughout the industry, when in fact, most of the costs of a contractor's losses are ultimately borne by that contractor. In gathering information for this study, it became apparent that few people in the insurance industry and even fewer contractors understand the details of how WCI premiums are calculated. WCI is the single largest controllable cost for contractors working in the U.S. It is well worth understanding.

The objective of this paper is to expose the true impact of a contractor's loss experience on its WCI costs and bottom line. When contractors realize they are paying for their own losses and are effectively self-insuring, they may have increased incentive to improve their safety performance. Construction automation and robotics may suddenly seem more attractive and cost effective. 


\section{WCI Premium Calculation}

Workers' compensation laws are governed by individual states and may vary from state to state, but all employers are required by law to provide some type of WCI for their employees. The vast majority of WCI premium dollars come from experience rated plans (Workers Compensation Premium 1991). The object of experience rated plans is to recognize "differences between individual insureds. It does this by comparing the experience of individual insureds with the average insured in the same classification, based on individual loss records, which may increase or decrease premium" (Manual 1992). For experience rated plans the WCI Standard Premium is based on the formula

$$
\text { Standard Premium = Manual Rate x Payroll Units x EMR }
$$

\section{Manual Rate}

The manual rate is based on the idea that the frequency of losses for a particular type of work is statistically predictable. The National Council on Compensation Insurance (NCCI) describes and assigns a four digit classification code to each of about 600 work classifications (Scopes 1991, Classification 1990). The manual rate gives a rough indication of the risk associated with each work classification. Naturally, some work classifications are more likely to result in injuries and fatalities than others, so manual rates vary among work classifications within each state. Manual rates also vary tremendously from state to state for each work classification. For common construction work classifications, manual rates range from about $\$ 3$ to more than $\$ 160$ per $\$ 100$ of straight time payroll. The U.S. construction industry average manual rate is about $\$ 28$ (Grogan 1993).

\section{Payroll Units}

Payroll units are found by dividing an employer's straight time direct labor cost by $\$ 100$. The logic of using straight time payroll rather than total payroll, which may include overtime and other premiums, is that the risk exposure associated with performing a certain type of work is a function of the time spent working, regardless of the hour of the day or the day of the week.

\section{Experience Modification Rating}

One of the objectives of workers' compensation legislation is to „encourage maximum employer interest in safety and rehabilitation through an appropriate experience rating mechanism" (Workers' Compensation Crisis 1991). The EMR accounts for the loss experience and other characteristics of each employer and is used to modify the manual rate. The purpose of the EMR is to help improve prediction of future losses based on past experience. Employers with poor safety records pay more for WCI than those with good safety records. Many employers do not know that their WCI premiums are a function of their own loss history. They incorrectly believe the risk is spread equally over a large number of insureds. The EMR not only tailors WCI premiums to the employer, it also provides an incentive for the employer to improve its safety record. Unfortunately, the incentive often gets lost in the complex method used to calculate the EMR.

The range of EMR values is generally between 0.50 and 2.00, although some contractors manage to earn EMRs as low as 0.35 and as high as 2.60 (Levitt and Samelson 1987). It is widely believed that an EMR of 1.00 means an employer has an average safety record, but this is not necessarily true and comparing different contractors' safety performance on the basis of EMR alone is simply not valid.

The experience period used in the rating process is the three year period ending one year prior to the date the modification becomes effective.

The NCCI EMR formula explained in the following is used by the 32 states over which the NCCI has jurisdiction. The remaining states can follow any procedure they choose for calculating the EMR, but most of them use methods similar or identical to the NCCI method. The EMR 
compares an employer's actual losses to its expected losses, with a number of adjustments. The NCCI EMR formula is:

\begin{tabular}{|c|c|c|c|c|c|c|c|}
\hline $\begin{array}{l}\text { Actual } \\
\text { Primary } \\
\text { Losses } \\
\end{array}$ & + & $\begin{array}{c}\text { Ballas } \\
t \\
\text { Value } \\
\end{array}$ & + & $\begin{array}{c}W x \\
\begin{array}{c}W x t u a l ~ E x c e s s \\
\text { Losses }\end{array} \\
\end{array}$ & + & $\begin{array}{c}(1-W) x \\
\text { Expected Excess } \\
\text { Losses }\end{array}$ & Total A \\
\hline $\begin{array}{l}\text { Expected } \\
\text { Primary } \\
\text { Losses }\end{array}$ & 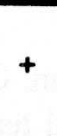 & $\begin{array}{c}\text { Ballas } \\
t \\
\text { Value }\end{array}$ & + & $\begin{array}{c}\text { Wx } \\
\text { Expected Excess } \\
\text { Losses }\end{array}$ & + & $\begin{array}{c}(1-W) x \\
\text { Expected Excess } \\
\text { Losses }\end{array}$ & al B \\
\hline
\end{tabular}

To get EMR, divide total A by total B and round to two decimal places (Experience 1992).

An important feature of the EMR calculation is that the cost of an injury is often a matter of luck and is statistically less predictable than the fact that the incident occurred. This is reflected in the EMR by giving greater weight to loss frequency than to loss severity.

The method used to reflect the relative importance of loss frequency and loss severity is called the ratable excess or split rating, where actual incurred losses are divided between primary and excess losses.

The first and third terms in the numerator of (2) are derived from an employer's own experience. Actual primary losses are a measure of the employer's loss frequency. For each actual loss equal to or less than $\$ 5,000$, the entire amount is used as the primary value. For each loss over $\$ 5,000$, the primary value is $\$ 5,000$.

Actual excess losses give an indication of the employer's loss severity history. For each actual loss, the actual excess loss is the difference between the actual loss and the actual primary loss, that is actual primary loss + actual excess loss $=$ actual loss. For large losses, the actual excess loss is the amount over $\$ 5,000$, subject to accident limits. For losses less than or equal to $\$ 5,000$, the actual excess loss is $\$ 0$.

The first and third terms in the denominator of (2) reflect the expected loss frequency and severity for a typical employer performing a certain classification of work. Again, the ratable excess method is used, where expected primary loss + expected excess loss $=$ expected loss. The expected loss for each work classification is calculated by multiplying an expected loss rate (ELR) for that classification by the appropriate payroll units. ELRs are found in tables published by state rating bureaus or private insurers.

The ratable excess calculation for actual losses is made separately for each incident using the $\$ 5,000$ limit discussed. The ratable excess calculation for expected losses is made for all expected losses collectively, using a value called the discount ratio or D-ratio. The D-ratio represents that portion of the expected losses that are expected primary losses: D-ratio x expected losses $=$ expected primary losses. Expected excess losses are the difference between expected losses and expected primary losses: expected primary losses + expected excess losses = expected losses. Tables listing the D-ratio for each work classification are published by state rating bureaus or private insurers. For most work classifications, the D-ratio is between 0.25 and 0.40 .

A weighting value $W$ determines the percentage of excess losses used in the EMR calculation. It is used to discount both actual excess losses and expected excess losses to give a ratable excess value. State rating bureaus or private insurers publish tables of $\mathrm{W}$ - values as a function of expected losses. W ranges between 0.07 for small employers and 0.63 for large employers. Because $\mathrm{W}$ is always less than 1.00 , the relative importance of excess losses, both actual and expected, is less than that of primary losses. This is the method used to emphasize loss frequency over loss severity.

The second term in both the numerator and denominator, the ballast value, helps stabilize the EMR against large changes from a single loss. By adding the same ballast value to both the numerator and denominator, the EMR tends to stay closer to 1.00 than it would otherwise. Ballast values are published in tables as a function of expected losses by state rating bureaus or private insurers. 
The fourth term in both the numerator and denominator of (2), (1-W) x expected excess losses, can be calculated from previously defined values. This term has the same effect as the ballast value, holding the EMR closer to 1.00 . While both of these stabilizing elements help smooth out changes in EMR from year to year, they set a lower limit for the EMR of an employer with no losses.

\section{EXample EMR Calculation}

The following example illustrates the calculation of the fictitious Simpson Construction Company's EMR for 1994. This example is designed to be as simple and general as possible so that major concepts can be understood. This example demonstrates the method used by the 32 NCCI states ( $A B C$ 's 1992) and is similar to the methods used in most of the remaining states.

The first step in the rating process is to enter the payroll and claim information on the experience rating form shown in Figure 1. This form is similar to the standard form used by the NCCI and most WCI carriers. Column 1 shows the four-digit classification codes for each type of work. Simpson performs four classifications of work: masonry NOC (code 5022), electrical wiring - interior (code 5190), concrete - residential (code 5215), and carpentry - 1 and 2 family residential (code 5645). Column 4 shows the straight-time payroll for each work classification for each year.

Column 7 shows the actual incurred losses, the total of the indemnity, medical, and rehabilitation costs, plus reserves. The actual incurred losses are entered without regard to classification code, so there is no connection between the entries in columns $1-4$ and those in columns 7 and 8 .

The actual incurred losses are split into primary and excess losses as described earlier. Column 8 shows the actual primary loss for each claim in column 7 . For example, the first claim shown is for $\$ 5,700$ of which $\$ 5,000$ is primary loss. For this claim, the actual excess loss is $\$ 700$, but it does not directly appear on this work sheet. In the third claim, for $\$ 3,700$, the entire amount is primary loss with $\$ 0$ excess loss. The actual incurred losses and actual primary losses are subtotaled for each year and the grand totals for the three year rating period are entered in boxes (g) and (h) respectively at bottoms of columns 7 and 8 . The total actual excess loss $(\$ 151,110)$, equal to the total actual incurred losses minus the total actual primary losses, is entered in box (d) at the bottom of column 4.

$\mathrm{Up}$ to this point, all the information has reflected the actual experience of Simpson and is shown in normal type. Information for a typical firm doing the same type of work as Simpson is shown in bold type. Column 2 shows the ELR for each work classification. For example, the ELR for code 5022, Masonry NOC, is 6.43. Column 3 shows the D-ratio for each work classification. The ELR and D-ratio values used in this example are taken from 1993 Michigan tables (Basic 1989). Column 5 shows expected losses, equal to ELR (column 2) x payroll (column $4) \div \$ 100$. Column 6 shows expected primary losses, equal to: D-ratio (column 3 ) $x$ expected losses (column 5). Expected losses and expected primary losses are totaled in boxes (e) and (f) at the bottoms of columns 5 and 6 , respectively. Box (C), at the bottom of column 3 , shows the total expected excess losses $(\$ 184,296)$, equal to box (e) minus box (f).

The $\mathrm{W}$ factor (0.27) appears in box (a) at the bottom of column 1 . The ballast value $(\$ 33,000)$ appears in box (b) at the bottom of column 2. The W factor and ballast values are based on total expected losses and are taken from 1993 Michigan tables (Basic 1989).

All the information needed to calculate the EMR has now been entered. The small table at the bottom of Figure 1 summarizes the information in the work sheet and roughly corresponds to the EMR formula in $(2)$. Actual $(\$ 90,500)$ and expected $(\$ 69,445)$ primary losses are transferred from boxes $(h)$ and $(f)$ respectively. The stabilizing value $(\$ 167,536)$ is the sum of the ballast value plus (1-W) $x$ expected excess losses $(\$ 33,000+(1-0.27) \times \$ 184,296)$. These correspond to the second and fourth terms in both the numerator and denominator of (2). 


\begin{tabular}{|c|c|c|c|}
\hline & MORIKERS' COLPE & W EXPERIENCE RATING & \\
\hline $\begin{array}{l}\text { Name of } \\
\text { Risk }\end{array}$ & Simpson Construction Company & $\begin{array}{ll}\text { Risk ID * } & 481092125 \\
\text { State } & \text { MI }\end{array}$ & $\begin{array}{r}\text { Effective Date } \\
01 / 01 / 1994\end{array}$ \\
\hline
\end{tabular}

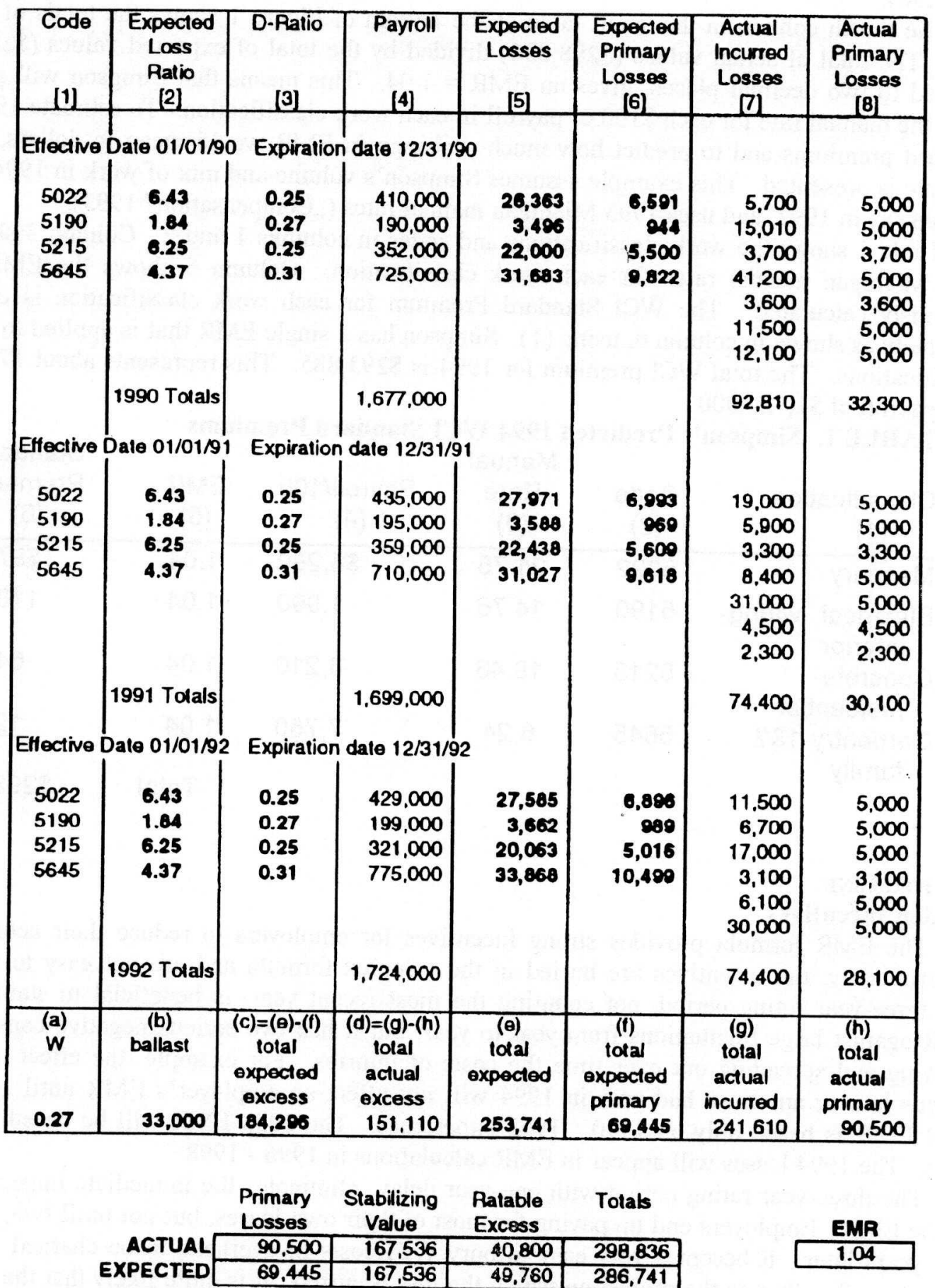

Figure 1. EMR Workshoet, Simpson's Actual and Expected date 
The ratable actual excess loss $(\$ 40,800)$ is equal to $\mathrm{W} x$ actual excess loss $(0.27 \times \mathbf{x} \$ 151,110)$. Similarly, the ratable expected excess loss $(\$ 49,760)$ is equal to $\mathrm{W} x$ expected excess loss $(0.27 \mathrm{x}$ $\$ 184,296$ ).

The fourth column in the small table at the bottom of Figure 1 shows the totals of the two rows. The total of actual values $(\$ 298,836)$ divided by the total of expected values $(\$ 286,741)$, rounded to two decimal places, gives an EMR $=1.04$. This means that Simpson will pay 1.04 times the manual rate for each $\$ 100$ of payroll in each work classification. To estimate $1994 \mathrm{WCI}$ standard premiums and to predict how much a change in EMR would mean in dollars, another example is presented. This example assumes Simpson's volume and mix of work in 1994 will be the same as in 1992, and uses 1993 Michigan manual rates („Compensation” 1993).

Table 1 shows the work classifications and codes in columns 1 and 2. Column 3 shows the 1993. Michigan manual rates for each work classification. Column 5 shows the EMR (1.04) previously calculated. The WCI Standard Premium for each work classification is computed separately as shown in column 6, using (1). Simpson has a single EMR that is applied to all work classifications. The total WCI premium for 1994 is $\$ 293,885$. This represents about $17 \%$ of the total payroll of $\$ 1,724,000$.

\begin{tabular}{|c|c|c|c|c|c|}
\hline $\begin{array}{l}\text { Classification } \\
\text { (1) }\end{array}$ & $\begin{array}{c}\text { Code } \\
(2)\end{array}$ & $\begin{array}{c}\text { Manual } \\
\text { Rate } \\
\text { (3) }\end{array}$ & $\begin{array}{c}\text { Payroll/100 } \\
\text { (4) }\end{array}$ & $\begin{array}{c}\text { EMR } \\
(5)\end{array}$ & $\begin{array}{l}\text { Standard } \\
\text { Premium } \\
\text { (6) }\end{array}$ \\
\hline Masonry & 5022 & 21.75 & $\$ 4,290$ & 1.04 & $\$ 97,040$ \\
\hline $\begin{array}{l}\text { Electrical wiring- } \\
\text { interior }\end{array}$ & 5190 & 14.76 & 1,990 & 1.04 & 118,966 \\
\hline Concrete- & 5215 & 19.46 & 3,210 & 1.04 & 64,965 \\
\hline Carpentry-1\&2 & 5645 & 6.24 & 7,750 & 1.04 & $\underline{12,914}$ \\
\hline family & & & & Total & $\$ 293,885$ \\
\hline
\end{tabular}

\section{BoTTOM LINE \\ Hidden Incentives}

The EMR formula provides strong incentives for employers to reduce their actual losses. Unfortunately, the incentives are buried in the complex formula and are not easy to recognize. The three-year rating period, not counting the most recent year, is beneficial in stabilizing the EMR against large fluctuations from year to year, but it has two serious negative consequences: delaying and spreading out over time the costs of injuries. For example, the effect of a single serious loss or an entire bad year in 1994 will not affect an employer's EMR until 1996. The 1994 EMR is based only on 1990 - 1992 experience. The 1995 EMR will be based on 1991 1993. The 1994 losses will appear in EMR calculations in 1996 - 1998.

The three-year rating period with one-year delay eliminates the immediate impact of losses on the EMR. Employers end up paying for most of their own losses, but not until two, three, and four years later. It becomes very easy to bury WCI costs in overhead to be charged against all projects, rather than to the project on which the loss occurred. It is quite likely that the project on which a loss occurred will be completed and the books closed by the time the EMR reflects the loss.

\section{Effect of EMR on WCI Costs}

By setting up Figure 1 and Table 1 in spreadsheet form, an employer can perform what-if analyses to estimate the effects of various types of losses on the firm's bottom line. The potential savings from a low EMR, or the potential penalty of a high EMR can easily mean the difference between winning and losing bids, making or losing money, and surviving or going out of business. 
If Simpson experienced absolutely no losses in the 1990 - 1992 rating period, its EMR would be 0.58 and its WCI Standard Premium would be „only" $\$ 163,897$. There is no upper limit, but employers with very high EMRs are unable to compete.

\section{True WCI Cost of Single Loss}

To illustrate the fallacy of the myth that WCI spreads the costs of losses among many firms, another example is presented which shows how much a single loss really costs the employer. If the $\$ 30,000$ claim, the last claim in column 7 of Figure 1, never happened, Simpson's EMR would drop from 1.04 to 1.00 , lowering the 1994 WCI premium from $\$ 293,885$ to $\$ 282,582$. This one claim, from back in 1992, costs Simpson $\$ 11,303$ in 1994. The effect of the claim will also be felt in 1995 and 1996. Assuming manual rates and payroll remain constant, the $\$ 30,000$ claim eventually costs Simpson $\$ 33,909$ (3 yr $\times$ \$11,303 per year). If manual rates increase, which is highly probable given recent history, or if Simpson's payroll grows due to wage inflation or company growth, the claim will cost even more. It is important to realize that this loss costs the employer nothing (in additional WCI premiums) in the year it occurs. The bills do not come due until two, three, and four years later.

\section{Loss Frequency versus Loss Severity}

To illustrate the strong emphasis of loss frequency over loss severity, another example assumes that the single $\$ 30,000$ claim from the Simpson example is replaced by five separate $\$ 5,000$ claims for a total of $\$ 25,000$. The EMR increases from 1.04 to 1.09 , and the WCI standard premium rises from $\$ 293,885$ to $\$ 308,014$, an increase of $\$ 14,129$ for 1994 alone. Even though the total actual incurred losses decrease by $\$ 5,000$, the contractor's WCI costs increase significantly in 1994, 1995, and 1996. Assuming that manual rates and payroll remain constant for 1995 and 1996, having five $\$ 5,000$ losses in 1992 eventually costs $\$ 42,387$ (3 x \$14,129) more than having one $\$ 30,000$ loss.

\section{Hidden Costs of Accidents}

Contractors should understand that the costs of losses used in WCI premium calculations include only the benefits paid by the WCI carrier to and on behalf of the injured employee. These costs, sometimes called the direct costs of accidents, are only the tip of the iceberg. As expensive as direct costs may be, there are many other so-called indirect costs that may far exceed the direct costs. Some of them are loss of productivity, disrupted schedules, administrative time, training replacements, wages for time not worked, clean up and repair, third party claims, equipment damage, lower morale, and loss of motivation. The indirect costs of accidents may range from one to 20 times the direct cost, but are often difficult to quantify (Accident 1993, Hinze 1992, Improving 1982, Oglesby et al 1989).

\section{ConCLUSION}

Some types of insurance protect the insured against catastrophic losses from events that never happen. Most people never have their homes burn down and are never involved in a fatal automobile collision. For many contractors, however, workers' compensation losses are not oncein-a-lifetime events; they happen several times every year. One of the objectives of WCI, to provide incentives to employers to improve their safety performance, has been lost in the complex method used to calculate premiums.

This paper has shown that contractors eventually pay for their losses, but the payment is delayed two to four years and spread over a three-year period. Many employers do not associate the cost of WCI with their own loss experience. Employers who understand how their WCI premiums are calculated will have far more incentive to improve safety and reduce losses. An understanding of the true costs of occupational injuries and fatalities makes construction automation and robotics more attractive and more cost-effective. 
The examples used in this paper focus on a few highlights of WCI standard premiums. For more examples and a more complete discussion of the examples in this paper the reader is referred to Everett and Thompson (1995).

APPENDIX. ReFERENCES

ABC's of Revised Experience Rating. (1992). National Council on Compensation Insurance (NCCI), Boca Raton, FL.

Accident Facts. (1993). National Safety Council, Chicago, Il.

Basic Manual for Michigan Workers' Compensation Insurance and Employers' Liability Insurance. (1989). Accident Fund of Michigan, Lansing, Mich.

Classification is Fundamental to Workers' Compensation Pricing. (1990). NCCI, Boca Raton, FL.

„Compensation insurance base rates." (1993). ENR, 231(13), 32-33.

Everett, J. G., and Thompson, W. S. (1995). „Experience Modification Rating for Workers' Compensation Insurance." J. Const. Engrg. and Mgmt., ASCE, 121(1).

Experience Rating Plan Manual. (1992). NCCI, Boca Raton, FL.

Grogan, T. (1993). „Costs keep climbing.” ENR, 231(13), 32-33.

Hinze, J, (1992). „Indirect costs are a major portion of jobsite injury costs." Concrete Construction, 37(3), 229.

Improving Construction Safety Performance. (1991). Report A-3, Business Roundtable, New York, N. Y.

„Insurance rates show few signs of change." (1984). ENR, 213(12), 104-105.

Korman, R. (1989) „Rate-making system blasted.” ENR, 223(12), 68-69.

Levitt, R. E. and Samelson, N. M. (1987). Construction Safety Management. McGraw-Hill, Inc., New York, N. Y.

Manual of Rules, Classifications and Interpretations for Workers' Compensation Insurance. (1992). International Risk Management Institute, Dallas, Texas.

Oglesby, C. H., Parker, H. W., and Howell, G. A. (1989). Productivity Improvement In Construction. McGraw-Hill, Inc., New York, N. Y.

Scopes of Basic Manual Classifications. (1991). NCCI, Boca Raton, FL.

Workers Compensation Premium, Finding the Perfect Fit. (1991). NCCI, Boca Raton, FL.

Workers' Compensation Crisis ... Safety Excellence Will Make A Difference. (1991). Business Roundtable, New York, N. Y. 